\title{
Promoting deep learning through project- based learning: a design problem
}

\author{
Emily C. Miller ${ }^{1}$ and Joseph S. Krajcik ${ }^{2^{*}}$ (1)
}

\begin{abstract}
In this paper, we present a design solution that involves the bringing together of Project-based Learning (PBL) with the theory of usable knowledge (Pellegrino \& Hilton, Developing transferable knowledge and skills in the 21st century, 2012). Usable knowledge is the ability to use ideas to solve problems and explain phenomena, an approach to science learning put forth by the Framework for K-12 Science Education (National Research Council (NRC), A framework for K-12 science education: Practices, crosscutting concepts, and core ideas, 2012) to optimize science learning environments. We offer a process for designing a curricular system that enhances how students learn science as a progression toward sophisticated practice of usable knowledge by focusing on coherence, depth, and motivation. We saw the potential of these distinct approaches for informing one another, and we extrapolate on 4 years of research that involves the process of iterating on our curricular design to best integrate the two approaches to support student learning.
\end{abstract}

Keywords: Project-based learning, Design-based research, Elementary science education, Environmental learning design, Deeper learning

\section{Promoting deep learning through project-based learning: a design problem ${ }^{1}$}

Our global community faces challenges of food security, access to potable water and threats such as climate change and habitat loss. Communities require scientifically literate citizens to make evidence-based decisions. All learners throughout the globe need to experience science education in which they develop the ability to use and apply scientific ideas and practices toward making decisions in science. The field calls for science learning environments that develop students' ability to explain natural events, and design solutions to challenges using science ideas and practices.

\footnotetext{
${ }^{1}$ The work discussed in this manuscript was funded by the George Lucas Educational Foundation. The George Lucas Educational Foundation did not contribute to the design of the study and collection, analysis, and interpretation of data and in writing the manuscript. All ideas, findings and perspectives are those of the authors and not of the George Lucas Educational Foundation.
}

* Correspondence: krajcik@msu.edu

${ }^{2}$ CREATE for STEM, Michigan State University, East Lansing, MI, USA Full list of author information is available at the end of the article
The capacity to enact knowledge to solve a problem requires a deeper level of science understanding than memorizing information or procedures. Knowledge-inuse is the capacity that learners need to apply knowledge to make decisions and solve problems, and to evaluate when and how to get more information when necessary (Pellegrino \& Hilton, 2012). The knowledge-in-use perspective presents a significant shift from traditional understandings of science knowledge as memorized facts and procedures and subsequently, to the teaching and learning of science. It is only through exposure to authentic disciplinary experiences with questions and problems with openended, and unresolved solutions, that students develop deeper, more connected level of knowledge (Schneider et al., 2016). In this way, students are tasked to leverage scientific and engineering practices for authentic purpose, the scientific ideas become tools, which are then harnessed toward arriving at the solution, rather than goals. The knowledge-in-use approach is similar to how the STEM world approaches science ideas in order to solve local and global issues. Knowledge-in-use perspective has gained prominence in the United States through the Framework for K-12 
Science Education (National Research Council (NRC), 2012). Reform documents in Finland, (Finnish National Board of Education (FNBE), 2015; Germany (Kulgemeyer \& Schecker, 2014) and PISA (OECD, 2016) emphasize similar knowledge-in-use theories of science learning in national standards. The emphasis on knowledge-in-use reflects an increased awareness by educators, learning scientists, policymakers, and the public of the facilities required by global citizens in the twenty-first Century.

We ask, "How do we design learning environments to support learners in developing knowledge-in-use to promote the deeper application of learning called for by international reform standards documents?

Third grade students are often tasked to write a report about an animal and describe how that animal survives in its habitat (e.g., Gillam, 2018; Leveen, 2007). Third graders will read nonfictions texts, take notes, and then record the same information in descriptive passages. In this case, science knowledge is considered as discreet information, and the basis for the final grade is the correctness and thoroughness of the information presented. Knowledge-in-use describes science knowledge as the application of big ideas of biology and habitat. Knowledge-in-use is related to the student conceptualizing the problem, and then subsequent collection and synthesis of data, and culminating in developing and defending their solution. Knowledge-in-use must revolve around an authentic problem, where there is more than one answer, such as engineering habitat to protect a species of butterfly.

Research from learning sciences (National Academies of Sciences, Engineering, and Medicine, 2019; NRC, 2007) supports the design of learning environments that engage students in authentic contexts where they make sense of natural phenomena by using disciplinary ideas and scientific and engineering practices. We propose that project-based learning (PBL) is one platform to promote the deeper learning of knowledge-in-use, which encompasses the vision of international reform documents.

In this paper, we elaborate on our four-year design process for developing PBL environments that promote a progression toward deep knowledge-in-use. As more and more national standards include similar approaches to learning, we realize that researchers from different countries are grappling with how to promote knowledge-in-use and could use use our process to inform their work. We developed a process that brings together the rigorous knowledge-in-use-based standards in the United States (National Academies of Sciences, Engineering, and Medicine, 2019; National Research Council (NRC), 2012; NRC, 2007), with the motivating, creative, and individualized advantages of PBL (Brown, Collins, \& Duguid, 1989). Through a reflective, iterative design and redesign process we envision an alliance between rigor and motivation. We aim to iterate a design that maximizes deeper learning of performance standards through highlighting affordances, and mitigating the drawbacks, of these two approaches to science knowledge and to learning environments. We present one solution designed to sustain student interest across time, and that simultaneously builds important learning goals anchored in national standards.

We encourage countries to modify the design principles we put forth to fit their environment and standards. In the spirit of collaboration, we are excited to find out how the design principles we offer here may contribute to the solutions being put forth in other countries.

\section{Example of standards that emphasize knowledge- in-use}

The Framework for K- 12 Science Education (National Research Council (NRC), 2012) and Science and Engineering for Grades 6-12: Investigation and Design at the Center (National Academies of Sciences, Engineering, and Medicine, 2019) build on learning theory (e.g., constructivism (Piaget, 1964) and situated cognition (Brown et al., 1989) to present a vision for science teaching and learning that moves classroom learning away from the acquisition of disconnected science concepts and memorized procedures to learning environments where students simultaneously develop disciplinary core ideas (DCIs), science and engineering practices, and crosscutting concepts -- to make sense of real-world phenomena or design solutions to problems. Disciplinary core ideas (DCIs) are central to the disciplines of science as they represent a few of the most key ideas of earth and space sciences, physical science, life science and engineering. Disciplinary core ideas are powerful intellectual tools as they allow individuals to explain and predict a host of phenomena, serve as tools for investigating and exploring more complex ideas and solving problems, and are the building blocks for learning within a discipline (Duncan, Krajcik, \& Rivet, 2016). Each DCI is useful in explaining a comprehensive range of natural phenomena and engineering problems. For example, ESS2.C: The Roles of Water in Earth's Surface Processes is a component idea of the larger DCI Earth's systems. ${ }^{2}$ Crosscutting concepts (CCCs), such as cause and effect and structure and function are ideas that occur within and across disciplinary boundaries and are applied as lenses to ask questions of any phenomena. Scientific and

${ }^{2}$ ESS stands for Earth and Space Science, which is the Science Discipline; The 2 is related to the Disciplinary Core Idea Earth's Systems; And the C denotes Component idea, Weather and Climate in The Framework for K-12 Science Education, pp. 171. (National Research Council (NRC), 2012) 
engineering practices are the ways of knowing and doing which scientists and engineers employ to study and explore the natural and designed worlds. Although each of the dimensions is important on its own, to make sense of phenomena or solve problems, the dimensions work together to support students in the process. This integration of the three dimensions is referred to as threedimensional learning (3D-learning).

The Next Generation Science Standards (NGSS; NGSS Lead State Partners, 2013) follow the vision of the Framework to present standards that incorporate all three dimensions: DCIs, SEPs and CCCs. Because each performance standard joins a practice with an idea and a crosscutting concept, they require students to use knowledge to explore or achieve something.

The 3D-learning of the NGSS is not intuitive and it is difficult for teachers to operationalize (Penuel, Harris, \& DeBarger, 2015). Teachers must change their teaching practice and understand learning as trajectory toward generative ideas while supporting practices that involve critical thinking about natural events. PBL presents a potentially accommodating platform for operationalizing this knowledge-in-use perspective. In PBL environments, the development of concrete artifacts to solve a meaningful problem is aligned with learning goals. In the same way that ideas are tools for making sense of a natural event, they can be employed for developing artifacts. The artifacts in PBL can motivate students to sustain in their cognitive work and stick with challenging ideas.

\section{Project-based learning}

PBL is grounded in major theoretical ideas: (1) active construction, (2) situated learning, (3) social interactions, and (4) cognitive tools (Bransford, Brown, \& Cocking, 2000). There are different versions of PBL (Barron et al., 1998; Krajcik et al., 1998), but all have in common the following: PBL uses a driving question that is meaningful to learners. This question drives student exploration and sustains motivation across time. Projects result in artifacts that are concrete and answers the driving question and culminates a learning sequence. Last, in PBL, the question and the artifact have an authentic connection to the community (Helle, Tynjälä, \& Olkinuora, 2006). Project-based learning can be a platform for social studies, science, technology, and increasingly for language literacy and mathematics contexts.

Research across these disciplines have refined PBL for meeting specific practices associated with those disciplines (Bell, 2010; Boaler, 2002; Krajcik \& Mun, 2014). In addition, discussions that bring together PBL approaches across disciplines is beginning. Project-based learning structures science learning environments around questions that engage students in collaborative sense-making of phenomena. Because PBL focuses on students and their interests, it tailors to the intellectual resources and experiences of diverse students and is responsive to culture, race, SES, and gender (Boaler, 2002; Geier et al., 2008; Krajcik, Blumenfeld, Marx, \& Soloway, 1994).

Project-based learning has acceptance by teachers and communities as an invigorating approach that motivates students to learn (Beneke \& Ostrosky, 2009; Chu, Tse, \& Chow, 2011). Teacher take-up of PBL is documented and when well supported by administration, there is success in the approach. Students will sustain in problem spaces, and their learning endeavors are fueled by construction, social contexts, and creative problem solving and community connection (Krajcik et al., 1994). PBL succeeds when teachers have autonomy, wherewithal, and flexibility to modify the pace of instruction, scaffold learning, and create differentiation (Barron et al., 1998). Teachers must rely on their own expertise to scaffold productive and equitable interactions among students from different demographic groups. To this end, researchers emphasize the need for principal support of teachers as experts who can leverage individualized understanding of their students (Lam, Cheng, \& Choy, 2010).

Current programs that feature school-wide models for PBL can be found across the United States as well in many other countries such as Finland, Germany, Israel, and Denmark (Schneider et al., 2016; Tal \& Miedijensky, 2005; Thomas, 2000). However, PBL models have not resolved questions of scale and sustainability, especially for less well-funded public schools (Coburn, 2003). They are often funded privately or featured in charter schools in the US, such as High Tech High, Think Global School, Envision Schools, My Tech High, Da Vinci Schools and schools associated with the Buck Institute for Education (Larmer, Ross, \& Mergendoller, 2009).

Challenges with scale, sustainability and PBL persist for the field, especially integrating PBL with reformbased standards or top-down initiatives (Coburn, 2003; Halvorsen et al., 2012). This may be due to the emphasis of PBL in individualism and creativity. Projects that are student-driven can become off track and result in lost teaching time in which academic standards are not met, and unproductive engagement (Blumenfeld et al., 1991). Barron et al. (1998) suggest one avenue to address curriculum standards through PBL. They included a design step in a PBL in which 5th grade students are to make a proposal for their design to a solution to rocket investigation. They compared two projects that engaged students in physics concepts, but one project included the step of submitting a rocket design according to specification from the National Aeronautics and Space Administration. The specification of the proposal guided students toward meeting content learning goals. 
Blumenfeld et al. (1991) also suggest that standards can be addressed in PBL. They call for research to designate lesson elements that are both fixed for the purpose of meeting standards, as well as elements that have flexibility and allow for student choice to remain true to PBL intent.

Despite the wide acceptance that PBL enjoys as curricular approach for students, PBL remains under researched (Halvorsen et al., 2012), especially in elementary education. Studies support PBL as motivating for students, and preliminary evidence indicates that PBL enhances student learning of challenging content and other skills such as problem solving and confidence (Kokotsaki, Menzies, \& Wiggins, 2016). A major call for the field has been to gather evidence that PBL environments correlate with student learning of knowledge-in-use standards in rigorous gold standard randomized control trials (Kokotsaki et al., 2016).

This bringing together of the PBL approach with the rigorous knowledge-in-use standards for designing student learning environments has been our team's ongoing work (Krajcik, Palincsar, \& Miller, 2015; Miller, Codere, Severance, \& Krajcik, 2019). We interrogate the process for capitalizing on two distinct approaches, one of student learning and another of learning environment design and pedagogies. Our effort is to develop a process for curricular systems (e.g., assessment, written curriculum and professional learning) that brings together the rigorous performances of the NGSS with the motivating, student centered approach of PBL. In this way, we hope to solve the challenges related to PBL: 1) tension in meeting standards, 2) scale and sustainability in multiple contexts, and 3) strong research support for the use of PBL in multiple contexts.

\section{Design-based research}

We use a design-based research method (Barab \& Squire, 2004) where we conjecture, build and test the theory of educational curricular system materials (Sandoval, 2014). The DBR method enables us to evaluate and refine innovations around persistent educational problems, impact classrooms, and simultaneously make substantial contributions to the research literature. The team has completed three distinct cycles of redesigning parts of the system of curriculum. Each cycle includes focus on problem and data analysis, and design or revision of theoretical framings and materials, implementation, and evaluation.

Our work is based on the Multiple-Literacies in Project-based Learning (ML-PBL) project that endeavors to design engaging learning environments for 3rd - 5th grades (upper elementary school) to improve science achievement, engagement, and social and emotional learning. ML-PBL is a designed-based learning environments that capitalize on PBL and the NGSS to:

- Engage all students in sense-making

- Use language literacy and mathematical tools to develop science understanding

- Design, develop and test a system for advancing science teaching and learning that builds a vision for enacting project-based learning and meeting NGSS for 3rd - 5th grades.

- The system includes:

$\circ$ Highly developed and specified educative teacher materials (i.e., how to promote discourse, use of the driving questions; scaffolded sequence of lessons)

- Highly developed and specified student materials (i.e., first-hand experiences, readings, writing experiences, model construction)

$\circ$ Professional learning supports (i.e., face-to-face meeting, video conferences, educative supports)

o 3-dimensional formative and end-of-unit assessments

- Support students to solve problems, think critically, develop creativity and think innovatively.

- Develop curriculum materials with both fixed and flexible elements so they can be translated across various school contexts to enable scalability. PBL curriculum design should be able to inform what components of principles need to fixed - or, in other words, "best practice" regardless of context and which design principles should be responsive and adaptive to different contexts.

To design, test and revise our materials, the ML-PBL group went through the following cycles of development, testing and revision. The first year of ML-PBL we conducted teaching experiments for the 3rd grade materials with just a few teachers to explore if the questions and phenomena we selected were compelling to learners. In the second year, we focused on pilot studies of the 3rd grade materials and teaching experiments of the 4th grade materials. Our pilot studies reached a greater number of teachers but still allowed us as researchers to watch closely what occurred in the classrooms. In the 3rd year, a field study with comparison teachers was conduct on the 3rd grade materials and pilot study of the 4th grade materials. Now in the 4th year, the Multiple Literacies Team has focused on an efficacy study with matched randomized controls of the Grade 3 units; revising and field-testing Grade 4 units; and teaching experiments of Grade 5 units.

In each cycle, we have focus classrooms in each grade where we collect rich ethnographic data, the primary source for evaluation and redesign of theory of 
integrated pedagogy materials for PBL and the NGSS. The thick data collection in these contexts responds to open ended research questions involving teacher and student discursive and collaborative practices, shifts in community, and science teaching and learning as MLPBL is enacted.

This paper presents the theoretical alignment and material development of PBL and the knowledge-in-use of the NGSS (ML-PBL). And we present our approach to motivating sustainability and scale, and coherence with fixed and flexible aspects of implementation for the current cycle, as we are currently engaged in the efficacy study. The findings of our work result in emerging theory for design features of project-based learning and the ongoing development of ML-PBL.

\section{PBL design to offer sustained focus in coherent material}

Standards based on a knowledge-in-use approach describe progressions in which the student demonstrates scientific understanding of ideas and practices with increasing sophistication over time. Development of such knowledge requires a coherent design of curriculum materials. Coherence is the careful design that builds the ability to apply knowledge over time, where not only the ideas are developing, but the scientific practices and problem solving capacity are mutually reinforced. In the PBL curriculum, application of knowledge must be supported over the span of the project as the final project is developed, revised and presented to the community.

Coherence involves the system of activity that develops over time, and is guided by common goal expectations and norms of the discipline (Ford \& Forman, 2006; Reiser, 2014). This practice builds by students collaboratively and incrementally developing and refining knowledge (Gouvea, Jamshidi, \& Passmore, 2014). Each time learners figure out additional, succeeding piece of knowledge, they add to the developing explanation, model, or designed solution. The activities shape a narrative that provides an intentional path toward building understanding, anchored in students' meaningful knowledge building experiences. In a coherent design, students have a reason for learning what they are learning (Edelson, 2001; Reiser, 2014), and are tasked to apply previous steps for accomplishing subsequent steps. Projectbased learning can be designed for the coherence and to inform the requisite perseverance for students to build robust scientific understandings over time.

An example of coherence is a description of a series of lessons involving protected birds in the area. Students are tasked to design a bird feeder for the protected bird. This project demonstrates coherence by engaging students in lessons to develop the following ideas sequentially:

1. Not all birds look the same and birds have different traits. This idea is developed through field research and data comparison.

2. Traits correspond to the environment that birds can survive in, and the resources that are available for the bird to access. This idea is developed through data analysis and argumentation about which body shape, feet and beaks are most suited to certain environments, and a resource inventory near the school.

3. Environments change throughout the year, changing the resources that are available, and some birds must adapt to these changes by migrating. This idea is developing through student creating models of phenology and mathematical thinking involving maps and migration patterns.

4. Students have three critical ideas necessary for designing a bird feeder, and none of the ideas could be deeply understood without the preceding focused engagement in the phenomenon.

\section{Bringing together project-based learning with knowledge-in-use}

The task in designing, developing and testing PBL instructional units is to create learning environments that will peak students' interests and drive them to learn and meet national standards (Schneider et al., 2016), designers need to pick complex and compelling phenomena and corresponding driving questions that will drive and sustain student learning and is thus an essential aspect of our work.

Establishing the driving question sets the stage for meeting all of the other key features of PBL and supporting learners in developing knowledge-in-use. The driving question focuses students' planning and carrying out collaborative investigations and guides the development of artifacts, which are concrete representations of the results of students' investigations. Throughout PBL, students collaborate and use cognitive tools in their investigations and in building artifacts that represent their emerging understandings. As such, the PBL classroom is a sense-making and knowledge-generating environment. Our design approach focuses on designing project-based learning environments that engage learners in pursuing questions about the natural world, design-based problems and natural events in which they live and meeting national standards, in our case the NGSS.

\section{PBL and the NGSS integrated design}

The integration of the PBL and the NGSS results in key generalizable approach for knowledge-in-use and 
curriculum and related instructional approached. In particular, we emphasize the usefulness of driving questions related to phenomenon and engineering solutions and the use of student ideas as cognitive tools that support knowledge building, driven by the discourse of sensemaking. Our design principles incorporate the PBL features and the learning goals of three-dimensional learning. We focused on picking phenomena and problems that meet standards, but at the same time compelling to the learner. The bold print represents the additions to the PBL features through integration with the NGSS and three-dimensional learning.

1. Lessons start with a driving question about a phenomenon and engineering problem, a problem to be solved or experience to be explained that promote wonderment about the world.

2. Lessons focus on Three-Dimensional learning goals (NGSS) that students are required to demonstrate mastery on key science standards and assessments.

3. Students participate in the Framework and the NGSS scientific practices - processes of investigating events and problem solving that are central to expert performance in the discipline.

4. Students explore the driving question by engaging in collaborative sensemaking activities to engage in shared knowledge building -- the solutions to the driving question.

5. While engaged in the practices of science, learning is scaffolded with discourse tools that help students participate in activities normally beyond their ability.

6. Overtime students iteratively and cohesively create a set of tangible products that scientifically address the driving question with increasing sophistication. These are shared artifacts, publicly accessible external representations of the class's learning with local impact.

The phenomena and problems in PBL that students make sense of are the drivers of an increasingly complex demand for figuring out the driving question that the students investigate throughout the unit (Krajcik \& Czerniak, 2018). Each new phenomenon or problem builds off the last and offers new insight toward the driving question. This careful and purposeful building meaning of phenomena through 3-D learning to acquire "usable" knowledge, builds coherence across the unit, and is what our team refined and iterated over time as a key solution to sustaining student engagement to develop knowledge-in-use. The artifact in ML-PBL is authentically connected to the community and solves a problem or explains a phenomenon in the design or natural world. The artifact leverages the engineering design solution and associated standards in the NGSS. Students must employ science ideas to collect information about a local science problem, develop a solution, test their solution and communicate their results to others.

We developed learning sets, or weekly coherent sets of lessons to help our teachers track the coherence of the lesson and across lessons that comprised the developing project. We included in learning sets driving questions of smaller grain-size toward the overarching driving question, usually comprising 5 lessons each. Each learning set, approximately 6 per unit, is responsive to the driving question, has its own tethered driving question and evidence statements. Evidence statements describe the learning that takes place in the lesson, and explicitly meet the goals of the lesson. As each learning set progresses, the understanding of the phenomenon is deepened, and the explanation becomes more sophisticated.

Each new learning set demands students deepen scientific understandings, referred to as conceptual tools (Blumenfeld et al., 1991), which they must use to make sense of the phenomenon (see Fig. 1) or solve the engineering problem (see Fig. 2). ${ }^{3}$ In the phenomenon driven units (see Fig. 1), the demand to make sense of the phenomenon has direct implications for the development of the artifact. In some instances, to motivate learning and sustain engagement over time, our units focus on a driving question that is problem driven (see Fig. 2). In the problem driven unit, the impetus to solve a problem motivates the need to explore and explain the phenomenon.

One third grade unit in ML-PBL engages learners in the driving question, "Why do I see so many squirrels but no stegosauruses?" This unit provides an authentic phenomenon for the students to explain (see Fig. 1). The students engage in a variety of investigations and modeling activities that include observing the squirrel outside, analyzing the structure of squirrels, making claims about how the needs of the squirrel relate to meeting its needs in the environments, and organizing and comparing information about squirrels and stegosauruses. The final artifact is a model that explains the stegosaurus's extinction event and the eutherian mammal survival story of the same time period. Students integrate all they have figured out about adaptations, traits, and interactions with the environment as well as the re-creation of the ancient prehistoric environments using fossils, to make an argument that changes in the environment might have caused the extinction of one animal and not the

\footnotetext{
${ }^{3}$ The figures use the abbreviation LS, which refers to Learning Set, the short series of lessons that address one or two specified performance expectations.
} 


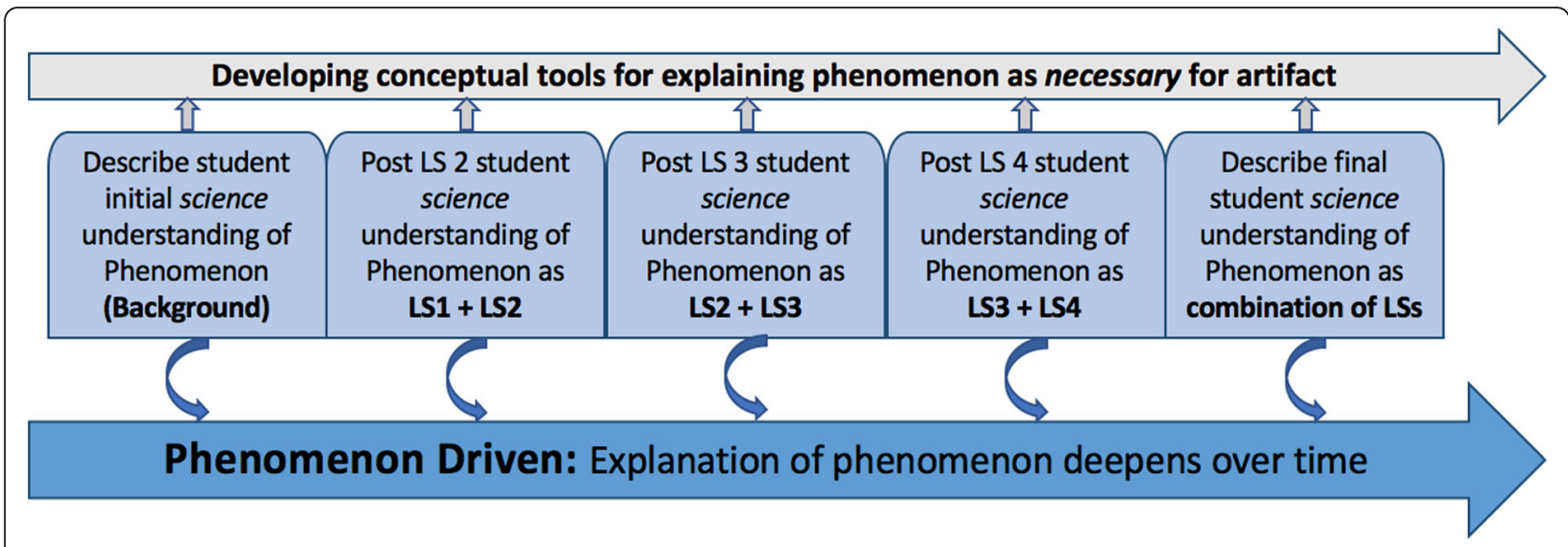

Fig. 1 How application of ideas as conceptual tools is developed and used over time to engage with a phenomenon

other. Another unit, entitled, "How can I help the birds in my community grow up and thrive", provides an authentic problem for the students to solve (see Fig. 2). The students engage in a variety of investigations and modeling activities that include bird observations and data collection, collecting information about birds - including traits, social behavior, life cycle, and ecology - modeling a chosen birds' response to change in weather and in climate, and designing a bird feeder for that bird. Thus, the students are motivated to sustain effort in deep science learning, propelled by their problem and through this engagement learning scientific ideas and practices key to the NGSS.

The original storyline (Krajcik \& Shin, 2013; Nordine, Krajcik, Fortus, \& Neumann, 2019) included the overarching driving question and lessons that built in sophistication as learners investigated the driving question. It also included the 3-D learning goals and the expectation that students would figure out phenomenon or solving problems that linked to the driving question. We adapted design components to become more responsive to the elementary setting and raised new questions about fixed and flexible design principles. Our efforts to embed creativity through multiple possible solutions of each driving question enrich the conversation about utility in broad and more specific contexts.

\section{Design for coherence to promote deeper, sustained learning}

For students to develop capacity for application of more sophisticated ideas, scientific practices and crosscutting concepts called for by the NGSS, they must leverage the motivating PBL practices to sustain attention and iterate on these applications. They need to learn to tolerate mistakes and recalibrate their use of ideas and modify representations to match the evidence. This is challenging for students and their teachers who support the learning. As such we need stronger evidence if PBL serves as an platform to design for the coherence and

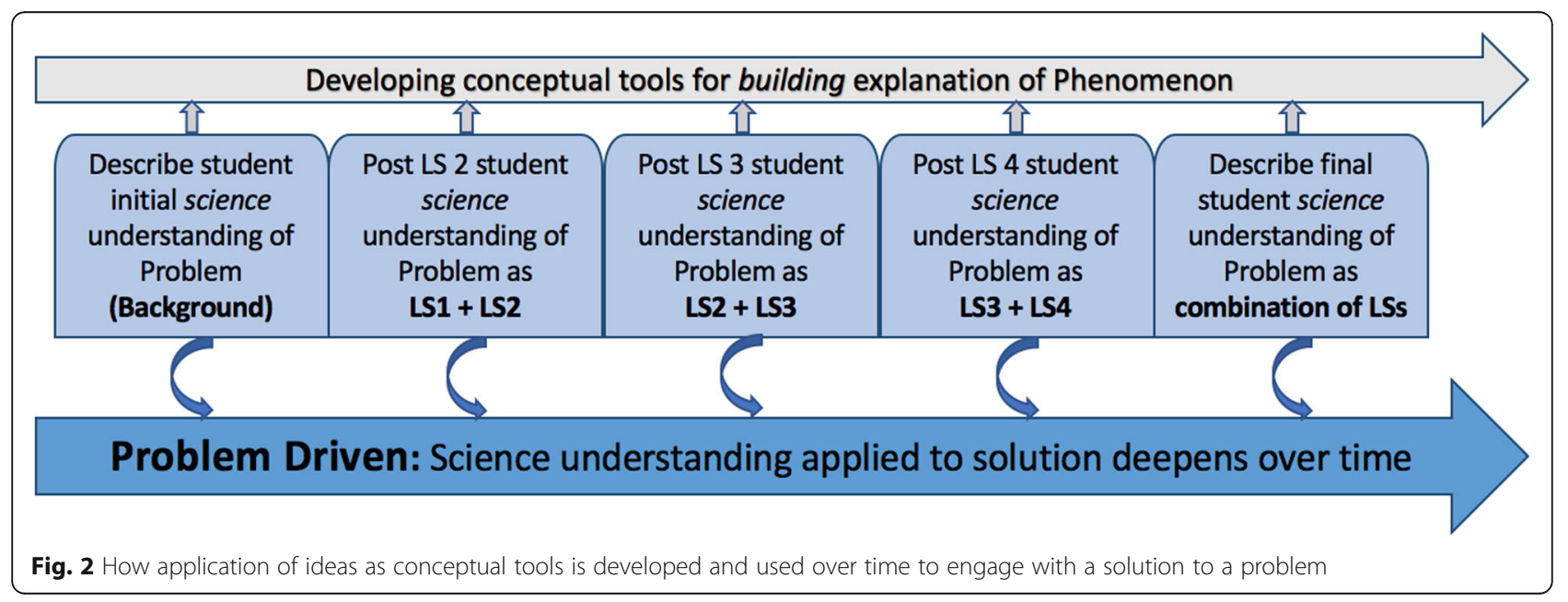


the requisite perseverance for students to build knowledge-in-use and thus robust understandings over time.

In our work, we revise the storyline approach by interrogating what is meant by coherence within units, across units, and across grade levels. Our research integrates learning of challenging science ideas aligned to the NGSS with students' engagement in science practices, language development, math, and technology. In addition, upper elementary is a context where students and teachers are steeped in communitybuilding and attention to equity. Last, we found that our upper elementary teachers were less familiar with science ideas, and less comfortable with teaching science, which impacted our educative supports and grain size of coherence. With this in mind, we designed the units to achieve across unit coherence and within unit coherence, which was divided into learning set coherences. In these ways, we found that the new context pushed our design process to be reshaped specific to elementary school context. We have become increasingly and reflexively:

- intentional about the coherence, within a unit and across units;

- purposeful in designing coherence in the enactment and artifacts -- building and using evidence statements in each lesson that adhere to the storyline and driving question;

- attentive to coherence with respect to integrations of science with language development and math ideas and practices, discourse supports, SEL, and cultural competencies (Ladson-Billings, 1995) thereby describing shared language and community being built over time;

- more attentive in creating community and responsive learning environments over time;

- more attention to smaller grain size coherence levels of within and across learning sets within the larger storyline. Grain size coherence characterizes consideration to lesson level, rather than learning set level, development of ideas.

PBL curriculum design using ML-PBL design features enhance and provides directions on developing PBL materials- or, in other words, best practice regardless of context to meet the three dimensions of learning contained in the NGSS--with design principles that are responsive and adaptive to different contexts, part of the student centered approach in PBL. With a focus on coherence, and aligning PBL with the NGSS, we have designed, enacted, researched, and revised units that promote rigorous knowledge that teachers can operationalize. Our design reshaped the PBL principles for utility in broad and more specific contexts (Miller et al., 2019).

\section{Conclusion}

Consistent with the call to lessen inequality and increase educational opportunities for all children (NRC, 2012; OECD, 2016), PBL can reshape science education by engaging all learners in meaningful and robust knowledge building experiences. As a paucity of robust research on PBL exists, the design prepared to advance the understanding of how to develop and design PBL environments and support all learners in developing deeper and more useable science knowledge. While we recognize PBL is not the only approach that can promote knowledge-in-use, PBL does show promise - still there are important questions for the field to answer. In particular, we need more rigorous evidence to support the use of PBL as promoting knowledge-in-use and scalable across contexts.

Multiple Literacies in Project-Based Learning (ML$\mathrm{PBL}$ ) resources employ features of PBL to design, develop and test NGSS aligned elementary learning environments with a coherent design that promotes student learning of the big ideas of science and social and emotional learning, with artifacts that connect to authentic community-based contexts. We have crafted teacher and student materials integrated with long-term professional learning. ML-PBL is unique in that it integrates multiple literacies (i.e., communicating with community, arguing data, modeling phenomena, design problems, and presentation of solution to older students and staff members and stakeholders) along with new ambitious standards in science (NGSS, Lead States, 2013) to support children in developing application or useable science knowledge (Pellegrino \& Hilton, 2012). A key feature of our work is the focus on students making sense of compelling and complex phenomena or designing solutions to problems. Everyday, place-based phenomena and problems are compelling to learning because they can spark and sustain interest. The coherent design with fixed and flexible features support learners in building usable knowledge of DCIs, CCCs and SEPs. Learners engage in collaboration and discourse to make sense of phenomena or problem in creative ways. We continue to review enactment to understand what features of the curriculum are associated with shifts in teacher practices, and which features correlate with deeper learning. While our design principles emerged from work in elementary classrooms, many of the principles our applicable to PBL environments at other grade levels (Schneider et al., 2016).

We add to the conversation in the field the tenacious or sticky problem of implementing theory in classrooms and recognizing the pull for dilution. Our ML-PBL design approach invigorates the learning through a 
coherent design that recognizes the need to purposeful and strategic introduction of related phenomenon and continued iteration of the artifact with new questions that supports students in developing useable knowledge. In addition, we propose that the NGSS and threedimensional learning benefit the PBL approach because the goal of deeper learning and artifact development coincide and mutually reinforce one another. We continue to seek models of teacher sense-making and community building in professional learning around productive struggle of implementation, and flexibility in practice for differentiation and context that enables creativity and responsiveness.

We continue to perfect the design --the tension between fixed and flexible elements in the flow of learning called for multiple trials. We continue to seek models of teacher sensemaking and community building in professional learning around productive struggle of implementation, and flexibility in practice for differentiation and context that enables creativity and responsiveness.

In the global community collaboration is a capacity we are all working to advance and strengthen. It's important for nations to come together and take on similar challenges of bringing together knowledge-in-use and designs that work to improve learning environments. We offer this design process for developing PBL and hope other countries use their own efforts to build toward this effort.

\section{Abbreviations \\ 3D-learning: Three-dimensional learning; CCCs: Crosscutting Concepts; DCIs: Disciplinary Core Ideas; ML-PBL: Multiple Literacies in Project-based Learning; NAS: National Academy of Science; NGSS: Next Generation of Science Standards; NRC: National Research Council; PBL: Project-Based Learning; SEPs: Scientific and Engineering Practices}

\section{Acknowledgements}

Not applicable.

\section{Authors' contributions}

Both authors read and approved the final manuscript.

\section{Author information}

Emily Miller is a Senior Researcher Consultant at Create for STEM, co-Principal Investigator on Multiple Literacies for Project-based Learning and ABD candidate in UW Madison.

Joe Krajcik is the Principal Investigator on Multiple Literacies for Project-based Learning, the Lappan-Philips Professor of Science Education and Director of CREATE 4 STEM at Michigan State University.

\section{Funding}

The work discussed in this manuscript was funded by the George Lucas Educational Foundation. The George Lucas Educational Foundation did not contribute to the design of the study and collection, analysis, and interpretation of data and in writing the manuscript. All ideas, findings and perspectives are those of the authors and not of the George Lucas Educational Foundation.

\section{Availability of data and materials}

All ML-PBL materials are Creative Commons Open Sources and are freely available for public use. The materials have the designation of Creative Commons Attribution-NonCommercial 4.0 International (CC BY-NC 4.0). Interested individuals can access the materials at https://open.mlpbl.com/\#/. Individuals interested in the data and supporting documents can contact the corresponding author.

\section{Competing interests}

The authors declare that they have no competing interests.

\section{Author details}

${ }^{1}$ University of Wisconsin-Madison, Madison, WI, USA. ${ }^{2}$ CREATE for STEM, Michigan State University, East Lansing, MI, USA.

Received: 3 May 2019 Accepted: 24 September 2019

Published online: 28 November 2019

\section{References}

Barab, S., \& Squire, K. (2004). Design-based research: Putting a stake in the ground. The Journal of the Learning Sciences, 13(1), 1-14.

Barron, B. J., Schwartz, D. L., Vye, N. J., Moore, A., Petrosino, A., Zech, L., \& Bransford, J. D. (1998). Doing with understanding: Lessons from research on problem-and project-based learning. Journal of the Learning Sciences, 7(3-4), 271-311.

Bell, S. (2010). Project-based learning for the 21st century: Skills for the future. The Clearing House, 83(2), 39-43.

Beneke, S., \& Ostrosky, M. M. (2009). Teachers' views of the efficacy of incorporating the project approach into classroom practice with diverse learners. Early Childhood Research \& Practice, 11(1), n1.

Blumenfeld, P. C., Soloway, E., Marx, R. W., Krajcik, J. S., Guzdial, M., \& Palincsar, A. (1991). Motivating project-based learning: Sustaining the doing, supporting the learning. Educational Psychologist, 26(3-4), 369-398.

Boaler, J. (2002). Learning from teaching: Exploring the relationship between reform curriculum and equity. Journal for Research in Mathematics Education, $239-258$.

Bransford, J. D., Brown, A. L., \& Cocking, R. R. (2000). How people learn, (vol. 11). Washington, DC: National academy press.

Brown, J. S., Collins, A., \& Duguid, P. (1989). Situated cognition and the culture of learning. Educational Researcher, 18(1), 32-42.

Chu, S. K. W. Tse, S. K. \& Chow, K. (2011). Using collaborative teaching and inquiry project-based learning to help primary school students develop information literacy and information skills. Library \& Information Science Research, 33(2), 132-143.

Coburn, C. E. (2003). Rethinking scale: Moving beyond numbers to deep and lasting change. Educational Researcher, 32(6), 3-12.

Duncan, R., Krajcik, J., \& Rivet, A. (Eds.) (2016). Disciplinary core ideas: Reshaping teaching and learning. Arlington: National Science Teachers Association Press.

Edelson, D. C. (2001). Learning-for-use: A framework for the design of technology-supported inquiry activities. Journal of Research in Science Teaching, 38(3), 355-385.

Finnish National Board of Education (FNBE) (2015). National core curriculum for general upper secondary schools 2015. Helsinki: Finnish National Board of Education (FNBE) Retrieved from http://www.oph.fi/saadokset_ja_ohjeet/ opetussuunnitelmien_ja_tutkintojen_perusteet/lukiokoulutus/lops2016/103/ O/lukion_opetussuunnitelman_perusteet_2015.

Ford, M. J., \& Forman, E. A. (2006). Redefining disciplinary learning in classroom contexts. Review of Research in Education, 30(1), 1-32.

Geier, R., Blumenfeld, P. C., Marx, R. W., Krajcik, J. S., Fishman, B., Soloway, E., \& Clay-Chambers, J. (2008). Standardized test outcomes for students engaged in inquiry-based science curricula in the context of urban reform. Journal of Research in Science Teaching: The Official Journal of the National Association for Research in Science Teaching, 45(8), 922-939.

Gillam, D. (2018). How do monarch butterflies find their way home? Science and Children, 55(6), 96-97.

Gouvea, J. S., Jamshidi, A., \& Passmore, C. (2014). Model-based reasoning: A framework for coordinating authentic scientific practice with science learning. Boulder: International Society of the Learning Sciences.

Halvorsen, A. L., Duke, N. K., Brugar, K. A., Block, M. K., Strachan, S. L., Berka, M. B. \& Brown, J. M. (2012). Narrowing the achievement gap in second-grade social studies and content area literacy: The promise of a project-based approach. Theory \& Research in Social Education, 40(3), 198-229.

Helle, L., Tynjälä, P., \& Olkinuora, E. (2006). Project-based learning in postsecondary education-theory, practice and rubber sling shots. Higher Education, 51(2), 287-314. 
Kokotsaki, D., Menzies, V., \& Wiggins, A. (2016). Project-based learning: A review of the literature. Improving Schools, 19(3), 267-277.

Krajcik, J., Blumenfeld, P. C., Marx, R. W., Bass, K. M., Fredricks, J., \& Soloway, E. (1998). Inquiry in project-based science classrooms: Initial attempts by middle school students. Journal of the Learning Sciences, 7(3-4), 313-350.

Krajcik, J. S., Blumenfeld, P. C., Marx, R. W., \& Soloway, E. (1994). A collaborative model for helping middle grade science teachers learn project-based instruction. The Elementary School Journal, 94(5), 483-497.

Krajcik, J. S., \& Czerniak, C. (2018). Teaching science in elementary and middle school classrooms: A project-based learning approach, (5th ed., ). New York \& London: Routledge, Taylor and Francis Group.

Krajcik, J. S., \& Mun, K. (2014). Promises and challenges of using learning technologies to promote student learning of science. Handbook of Research on Science Education, 2, 337-360.

Krajcik, J. S., Palincsar, A., Miller, E. (2015). Multiple literacy in project-based learning. Michigan State University, East Lansing Ml; Lucas education research, a division of the George Lucas Educational Foundation, San Rafael, CA

Krajcik, J. S., \& Shin, N. (2013). Project-based learning. In R. K. Sawyer (Ed.), The Cambridge handbook of learning sciences, (2nd ed., ). New York: Cambridge.

Kulgemeyer, C., \& Schecker, H. (2014). Research on educational standards in German science education-Towards a model of student competences EURASIA. Journal of Mathematics, Science \& Technology Education, 10(4), 257-269.

Ladson-Billings, G. (1995). Toward a theory of culturally relevant pedagogy. American Educational Research Journal, 32(3), 465-491.

Lam, S. F., Cheng, R. W. Y., \& Choy, H. C. (2010). School support and teacher motivation to implement project-based learning. Learning and Instruction, 20(6), 487-497.

Larmer, J., Ross, D., \& Mergendoller, J. (2009). Project based learning (PBL) starter kit: To-the-point advice, tools and tips for your first project in middle or high school. Novato: Buck Institute for Education.

Leveen, L. (2007). Exploring animals, Glossopedia style. Science and Children, 45(1), $48-51$.

Miller, E., Codere, S., Severance, S., \& Krajcik, J. (2019). Aligning PBL with the NGSS: What do the NGSS offer PBL. Paper presented in Krajcik, J. In Promoting and Measuring Student Learning and Engagement Through Project-Based Learning: Leveraging Coherence. Toronto: AERA.

National Academies of Sciences, Engineering, and Medicine (2019). Science and engineering for grades 6-12: Investigation and design at the center. Washington, DC: National Academies Press.

National Research Council (NRC) (2012). A framework for K-12 science education: Practices, crosscutting concepts, and core ideas. Washington, DC: National Academies Press.

NGSS Lead State Partners (2013). Next generation science standards: For states, by states. Washington, DC: The National Academies Press.

Nordine, J., Krajcik, J., Fortus, D., \& Neumann, K. (2019). Using storylines to support three-dimensional learning in project-based science. Science Scope, 42(6), 85-91.

OECD (2016). PISA 2015. In Assessment and analytical framework: Science, reading, mathematic and financial literacy. Paris: OECD Publishing.

Pellegrino, J. W., \& Hilton, M. L. (2012). Developing transferable knowledge and skills in the 21st century. Washington, DC: National Research Council.

Penuel, W. R., Harris, C. J., \& DeBarger, A. H. (2015). Implementing the next generation science standards. Phi Delta Kappan, 96(6), 45-49.

Piaget, J. (1964). Part I: Cognitive development in children: Piaget development and learning. Journal of Research in Science Teaching, 2(3), $176-186$.

Reiser, B. J. (2014). Designing coherent storylines aligned with NGSS for the K-12 classroom. Boston: National Science Education Leadership Association http://bit.ly/1TZeSaG

Sandoval, W. (2014). Conjecture mapping: An approach to systematic educational design research. Journal of the Learning Sciences, 23(1), 18-36.

Schneider, B., Krajcik, J., Lavonen, J., Salmela-Aro, K., Broda, M., Spicer, J., ... Viljaranta, J. (2016). Investigating optimal learning moments in US and Finnish science classes. Journal of Research in Science Teaching, 53(3), 400-421.

Tal, R. T., \& Miedijensky, S. (2005). A model of alternative embedded assessment in a pull-out enrichment program for the gifted. Gifted Education International, 20(2), 166-186.
Thomas, J. W. (2000). A review of research on project-based learning.

\section{Publisher's Note}

Springer Nature remains neutral with regard to jurisdictional claims in published maps and institutional affiliations.

\section{Submit your manuscript to a SpringerOpen ${ }^{\circ}$ journal and benefit from:}

- Convenient online submission

- Rigorous peer review

- Open access: articles freely available online

- High visibility within the field

- Retaining the copyright to your article

Submit your next manuscript at $\boldsymbol{\nabla}$ springeropen.com 